\title{
OFFSHORE WIND POWER POTENTIALS IN THE SETO INLAND SEA
}

\author{
Shinji HIEJIMA ${ }^{1}$ and Yuuichi HIYOSHI ${ }^{2}$ \\ 1 Associate Professor, Graduate School of Environmental Science, Okayama University \\ (1-1,Tsushima-Naka, 3-chome, Okayama 700-8530, Japan) \\ E-mail: hiejima@cc.okayama-u.ac.jp \\ 2 Graduate School of Environmental Science, Okayama University \\ (1-1,Tsushima-Naka, 3-chome, Okayama 700-8530, Japan) \\ E-mail: gev19322@s.okayama-u.ac.jp
}

\begin{abstract}
The Seto Inland Sea is an appropriate place for offshore wind power generation due to its features of vast shallow waters, numerous islands, calm ocean waves, steady breeze circulation and so on. In this study, offshore wind energy potential in the Seto Inland Sea is estimated based on the wind prediction data of LAWEPS, and the sea areas appropriate for offshore wind power generation are extracted by means of GIS analysis considering the constrained conditions such as wind speed, water depth, natural parks and ship lanes. The results of the estimation show that the maximum annual power generation is $247 \mathrm{TWh}$ and the minimum is 32 TWh. In particular, the Suo-Nada area near the Kanmon Channel seems to be highly promising as the offshore wind power generation site.
\end{abstract}

Key Words : wind power generation, offshore wind power, Seto Inland Sea, GIS, LAWEPS

\section{INTRODUCTION}

Recently the development of wind energy resource has been increasing globally. In particular, offshore wind energy appears very promising because the wind condition is more stable and the wind speed is much higher than onshore. Japan is surrounded by oceans and the total extension of its coastlines is the second longest in the world. This means that abundant wind energy resource lies unused around us. However, shallow waters appropriate for offshore wind turbine construction are limited around Japan. In addition, Japanese fishery industry is very active, and thus conflictions with the fishery industry are likely to occur during the construction and the operation phases of offshore wind farms.

The Seto Inland Sea has not been considered as the appropriate place for wind power generation. However, it has many advantages for offshore wind power generation such as vast shallow waters of $30 \mathrm{~m}$ average depth, numerous islands where the wind speed is as high as offshore, calm ocean waves, steady breeze circulation and so on. Considering such circumstantial advantages of the Seto Inland Sea, we have proposed "Offshore Wind Farm Plan for Seto Inland Sea"1). This conceptual plan aims to provide not only clean energy resource but also various circumstantial benefits to activate the local societies around the Seto Inland Sea.

In this study, offshore wind energy potential in the Seto Inland Sea is estimated based on the wind prediction data of LAWEPS ${ }^{2}$. In addition, the sea areas appropriate for offshore wind power generation are extracted considering the constrained conditions such as wind speed, water depth, natural parks and ship lanes

\section{ESTIMATION METHOD}

\section{(1) Consideration of constrained conditions}

Geographical Information System (GIS) ${ }^{3)}$ is used to investigate the sea areas appropriate for offshore wind power generation in the Seto Inland Sea. As the constrained conditions to extract the appropriate sea 


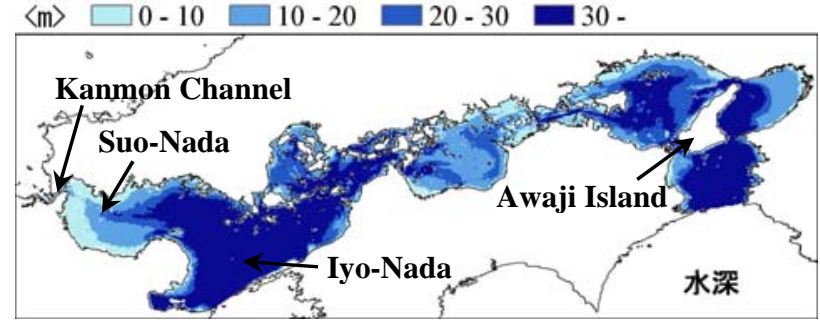

(a) Water depth

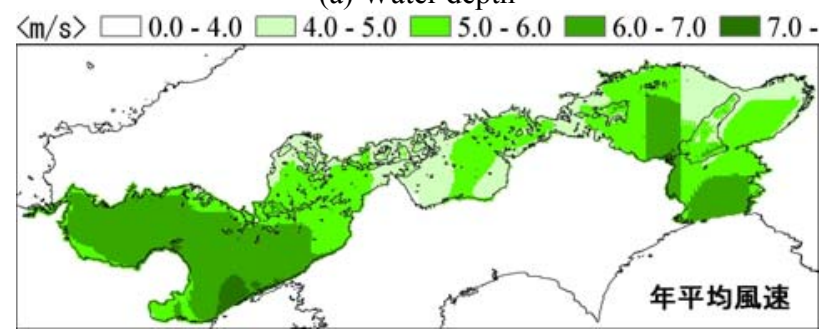

(b) Annual mean wind speed (70m height)

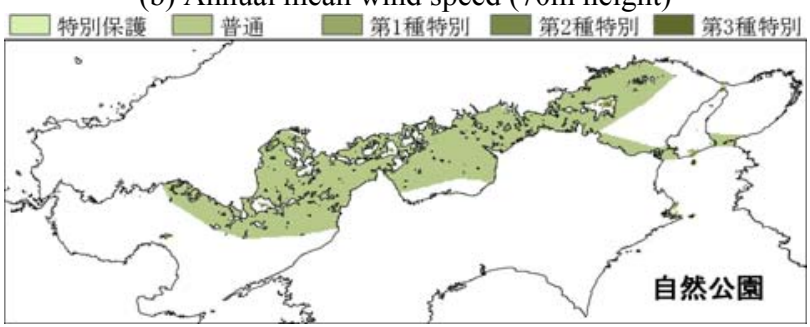

(c) Natural park

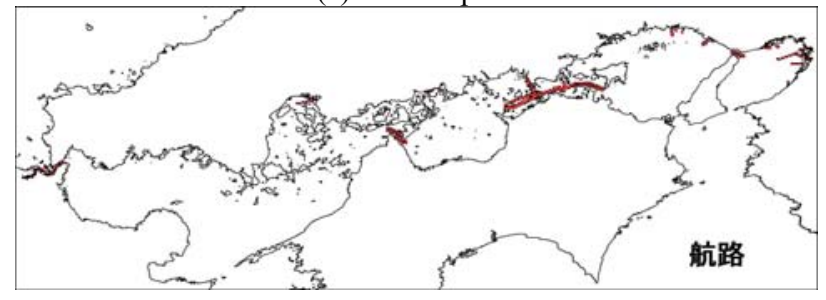

(d) Ship lane

Fig.1 Distribution maps of constrained conditions

areas from the whole area of the Seto Inland Sea, the water depth, the annual mean wind speed, the natural park areas and the ship lanes are considered in the GIS analysis. The distribution maps of the water depth, the annual mean wind speed, the natural park and the ship lanes in the Seto Inland Sea are shown in Fig.1.

In order to construct offshore wind turbines, shallow waters less than $30 \mathrm{~m}$ are necessary. It is found that the shallow water areas less than $30 \mathrm{~m}$ occupy approximately $70 \%$ of the whole sea area and even those less than $20 \mathrm{~m}$ are more than $50 \%$ in Fig.1(a). There are many shallow waters appropriate for the offshore wind turbine construction in the Seto Inland Sea.

The annual mean wind speed distribution at $70 \mathrm{~m}$ height above the sea level in Fig.1(b) reveals that the wind speed is high in the eastern and western part of the Seto Inland Sea and relatively lower in the central area. From the viewpoint of economical feasibility, the sea areas of the annual mean wind speeds higher than $5 \mathrm{~m} / \mathrm{s}$ and $6 \mathrm{~m} / \mathrm{s}$ are extracted in the GIS analysis.

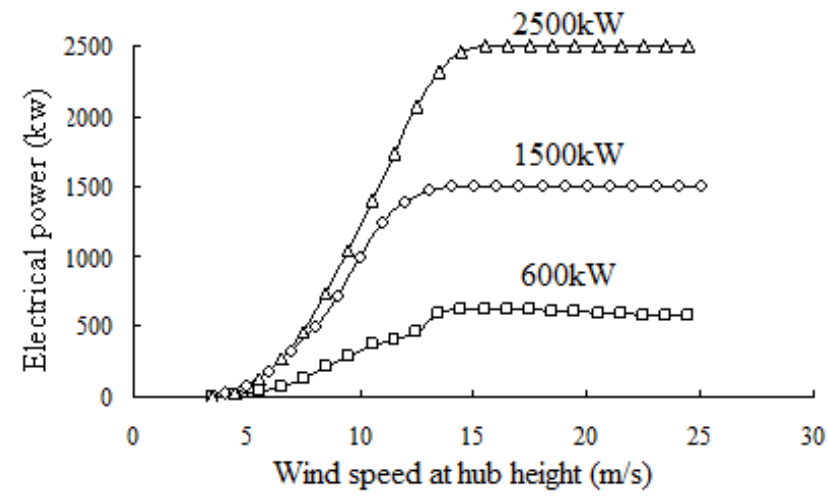

Fig.2 Power curves of wind turbines

The natural park areas in Fig.1(c) are widely distributed in the central area of the Seto Inland Sea, and then they do not overlap with the high wind speed areas. The natural park is classified into the four categories, which are the special protection zone (SP), the first class area ( $\mathrm{C} 1)$, the second class area (C2), the third class area (C3) and the normal class area $(\mathrm{CN})$. Most of the natural park areas in Fig.1(c) belong to the normal class area. The ship lanes are few and lie linearly in Fig.1(d), and hence they are likely to have negligible effects on the wind turbine installation.

\section{(2) Calculation of electric power production}

Annual electric power production $P_{W}$ of a wind turbine is calculated as

$$
P_{W}=\sum[P(V) \times f(V) \times 8760]
$$

where 8760 is the total number of hours in a year. $P(V)$ is the possible power generation of a wind turbine at the wind speed of $V . P(V)$ is obtained from the power curves shown in Fig.2. In this study, three scales of wind turbines with the rated power of $600 \mathrm{~kW}, 1500 \mathrm{~kW}$ and $2500 \mathrm{~kW}$ are employed. $f(V)$ is the occurrence ratio of the wind speed $V$, and it is described by the following Weibull distribution function.

$$
f(V)=k / c(V / c)^{(k-1)} \exp \left[-(V / c)^{k}\right]
$$

where the Weibull coefficients $k$ and $c$ are given by the wind prediction data of LAWEPS.

Assuming that the wind turbines of $70 \mathrm{~m}$ height above the sea level are placed at intervals of $520 \mathrm{~m}$, total electric power production is estimated by the summation of each power production of the wind turbines. In order to evaluate the economic feasibility, the capacity factor $F_{C}$ of a wind turbine with the rated power $R P$ is calculated as follows.

$$
F_{C}=\frac{P_{W}}{R P \times 8760} \times 100(\%)
$$




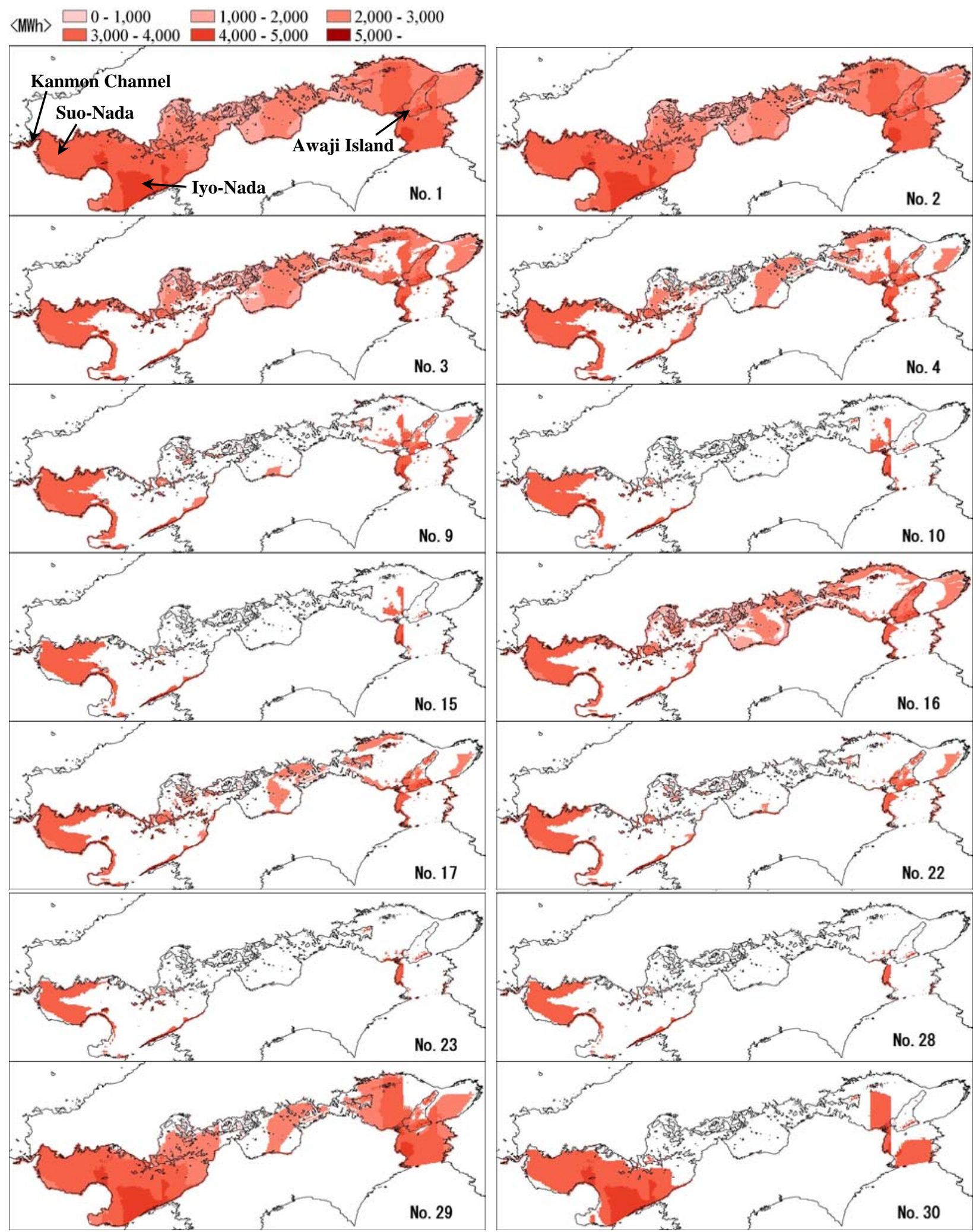

Fig.3 Distribution maps of possible annual electric power production of the representative cases in Table 1

\section{(3) Calculation of power generating cost based on} underwater substructure

In general, the construction costs of offshore wind turbines are higher than those of onshore wind turbines. This is due to the high-cost underwater substructures of offshore wind turbines. The construction costs of the underwater substructures depend on the water depth. Accordingly, the construction cost $C_{S}$ of the underwater substructure is calculated as a function of the water depth, and then the power generating cost $C_{G}$ based on the underwater substructure is evaluated as 


$$
C_{G}=C_{S} / P_{W}(\text { yen } / \mathrm{kwh})
$$

\section{ESTIMATION RESULTS}

\section{(1) Possible electric power production}

Possible annual electric power production is estimated in the whole area of the Seto Inland Sea and the partial areas extracted from the whole area based on the various combinations of the forementioned constrained conditions. The estimation results employing the wind turbine with the rated power of $1500 \mathrm{~kW}$ are shown in Table 1. In this table, possible annual electric power productions of each case and their ratios to $55.4 \mathrm{TWh}$, which is the annual electric power supply of the whole Chugoku district in the fiscal 2003, are listed. Fig.3 shows the distribution maps of the possible annual electric power productions corresponding to the representative cases in Table 1. The colored areas in Fig.3 indicate the sea areas extracted under the constrained conditions in Table 1, and the blanked ones are the excluded areas.

Case1, which is the case without any constrained conditions, reveals that the possible electric power production in the whole Seto Inland Sea exceeds $400 \%$ of the electric power supply of the Chugoku district. This means that extremely abundant wind energy lies as unused energy in the Seto Inland Sea.

Case 3 and Case 16 show that the possible electric power productions limited in the shallow waters decrease approximately to $60 \%$ and $40 \%$ of Case 1 , respectively. However, they exceed $200 \%$ of the electric power supply of the Chugoku district, and the wind energy potential is still high.

The sea areas where the annual mean wind speeds are higher than $5 \mathrm{~m} / \mathrm{s}$ occupy approximately $70 \%$ of the whole sea area, while those higher than $6 \mathrm{~m} / \mathrm{s}$ drastically decrease to $30 \%$. Accordingly the possible electric power production of Case 30 also decreases considerably compared to Case29. This difference can also be recognized from the comparison between their distribution maps in Fig.3. These results indicate that the wind speeds are less than $6 \mathrm{~m} / \mathrm{s}$ in most areas of the Seto Inland Sea, and hence active utilization of the wind energy with $5 \mathrm{~m} / \mathrm{s}$ level is very important.

Although the natural park areas, which are distributed in the central area of the Seto Inland Sea, do not overlap with the high wind speed areas, they overlap with many sea areas with the wind speeds of $5 \mathrm{~m} / \mathrm{s}$ level. This can be recognized from the differences of the possible electric power production between Case4, Case9, Case10 and Case15 or between Case17, Case22, Case23 and Case28.

Case28 shows the result of the strictest
Table 1 Estimated electric power production (Wind turbine with the rated power of $1500 \mathrm{~kW}$ )

\begin{tabular}{|c|c|c|c|c|c|c|}
\hline $\begin{array}{l}\text { Case } \\
\text { No. }\end{array}$ & $\begin{array}{l}\text { Water } \\
\text { Depth } \\
\text { (m) }\end{array}$ & $\begin{array}{l}\text { Wind } \\
\text { Speed } \\
(\mathrm{m} / \mathrm{s})\end{array}$ & Natural Park & $\begin{array}{l}\text { Ship } \\
\text { Lane }\end{array}$ & \begin{tabular}{|c|} 
Power \\
Production \\
(TWh)
\end{tabular} & $\begin{array}{c}\text { Power Ratio } \\
\text { in Chugoku } \\
(\%)\end{array}$ \\
\hline 1 & - & - & - & No & 247 & 445.4 \\
\hline 2 & - & - & - & Yes & 244 & 441.0 \\
\hline 3 & $\leq 30$ & - & - & Yes & 143 & 257.5 \\
\hline 4 & $\leq 30$ & $\geq 5$ & - & Yes & 107 & 193.5 \\
\hline 5 & $\leq 30$ & $\geq 5$ & SP & Yes & 107 & 193.4 \\
\hline 6 & $\leq 30$ & $\geq 5$ & $\mathrm{SP}, \mathrm{C} 1$ & Yes & 107 & 193.4 \\
\hline 7 & $\leq 30$ & $\geq 5$ & $\mathrm{SP}, \mathrm{C} 1, \mathrm{C} 2$ & Yes & 105 & 190.9 \\
\hline 8 & $\leq 30$ & $\geq 5$ & $\mathrm{SP}, \mathrm{C} 1, \mathrm{C} 2, \mathrm{C} 3$ & Yes & 105 & 190.0 \\
\hline 9 & $\leq 30$ & $\geq 5$ & $\begin{array}{c}\mathrm{SP}, \mathrm{C} 1, \mathrm{C} 2 \\
\mathrm{C} 3, \mathrm{CN}\end{array}$ & Yes & 70 & 127.4 \\
\hline 10 & $\leq 30$ & $\geq 6$ & - & Yes & 47 & 84.3 \\
\hline 11 & $\leq 30$ & $\geq 6$ & SP & Yes & 47 & 84.3 \\
\hline 12 & $\leq 30$ & $\geq 6$ & $\mathrm{SP}, \mathrm{C} 1$ & Yes & 47 & 84.2 \\
\hline 13 & $\leq 30$ & $\geq 6$ & $\mathrm{SP}, \mathrm{C} 1, \mathrm{C} 2$ & Yes & 46 & 83.8 \\
\hline 14 & $\leq 30$ & $\geq 6$ & $\mathrm{SP}, \mathrm{C} 1, \mathrm{C} 2, \mathrm{C} 3$ & Yes & 46 & 83.5 \\
\hline 15 & $\leq 30$ & $\geq 6$ & $\begin{array}{c}\mathrm{SP}, \mathrm{C} 1, \mathrm{C} 2 \\
\mathrm{C} 3, \mathrm{CN}\end{array}$ & Yes & 43 & 76.9 \\
\hline 16 & $\leq 20$ & - & - & Yes & 113 & 203.2 \\
\hline 17 & $\leq 20$ & $\geq 5$ & - & Yes & 82 & 148.4 \\
\hline 18 & $\leq 20$ & $\geq 5$ & SP & Yes & 82 & 148.4 \\
\hline 19 & $\leq 20$ & $\geq 5$ & SP, C1 & Yes & 82 & 148.3 \\
\hline 20 & $\leq 20$ & $\geq 5$ & $\mathrm{SP}, \mathrm{C} 1, \mathrm{C} 2$ & Yes & 81 & 145.8 \\
\hline 21 & $\leq 20$ & $\geq 5$ & $\mathrm{SP}, \mathrm{C} 1, \mathrm{C} 2, \mathrm{C} 3$ & Yes & 80 & 145.0 \\
\hline 22 & $\leq 20$ & $\geq 5$ & $\begin{array}{c}\mathrm{SP}, \mathrm{C} 1, \mathrm{C} 2, \\
\mathrm{C} 3, \mathrm{CN}\end{array}$ & Yes & 56 & 100.3 \\
\hline 23 & $\leq 20$ & $\geq 6$ & - & Yes & 35 & 63.5 \\
\hline 24 & $\leq 20$ & $\geq 6$ & $\mathrm{SP}$ & Yes & 35 & 63.5 \\
\hline 25 & $\leq 20$ & $\geq 6$ & $\mathrm{SP}, \mathrm{C} 1$ & Yes & 35 & 63.4 \\
\hline 26 & $\leq 20$ & $\geq 6$ & $\mathrm{SP}, \mathrm{C} 1, \mathrm{C} 2$ & Yes & 35 & 63.0 \\
\hline 27 & $\leq 20$ & $\geq 6$ & $\mathrm{SP}, \mathrm{C} 1, \mathrm{C} 2, \mathrm{C} 3$ & Yes & 35 & 62.7 \\
\hline 28 & $\leq 20$ & $\geq 6$ & $\begin{array}{c}\mathrm{SP}, \mathrm{C} 1, \mathrm{C} 2 \\
\mathrm{C} 3, \mathrm{CN}\end{array}$ & Yes & 32 & 57.5 \\
\hline 29 & - & $\geq 5$ & - & Yes & 205 & 369.7 \\
\hline 30 & - & $\geq 6$ & - & Yes & 115 & 206.7 \\
\hline
\end{tabular}

combination of the constrained conditions, and thus most areas of the Seto Inland Sea are excluded as shown in Fig.3. However, its possible electric power production can satisfy almost $60 \%$ of the electric power supply of the Chugoku district. From the comprehensive perspective, the Suo-Nada area near the Kanmon Channel seems to be highly promising as the offshore wind power generation site.

\section{(2) Economic feasibility}

Fig.4 shows the distribution maps of the possible annual electric power production employing the wind turbine with the rated power of $600 \mathrm{~kW}, 1500 \mathrm{~kW}$ and $2500 \mathrm{~kW}$, and their capacity factors are shown in Fig.5. Although the possible electric power production increases according to the scale of the rated power, the capacity factor is the highest at the rated power of $1500 \mathrm{~kW}$. This is because the wind turbine with the rated power of $1500 \mathrm{~kW}$ has relatively higher output performance than the other wind turbines in the low wind speeds as shown in Fig.2. These results mean that the installation of 


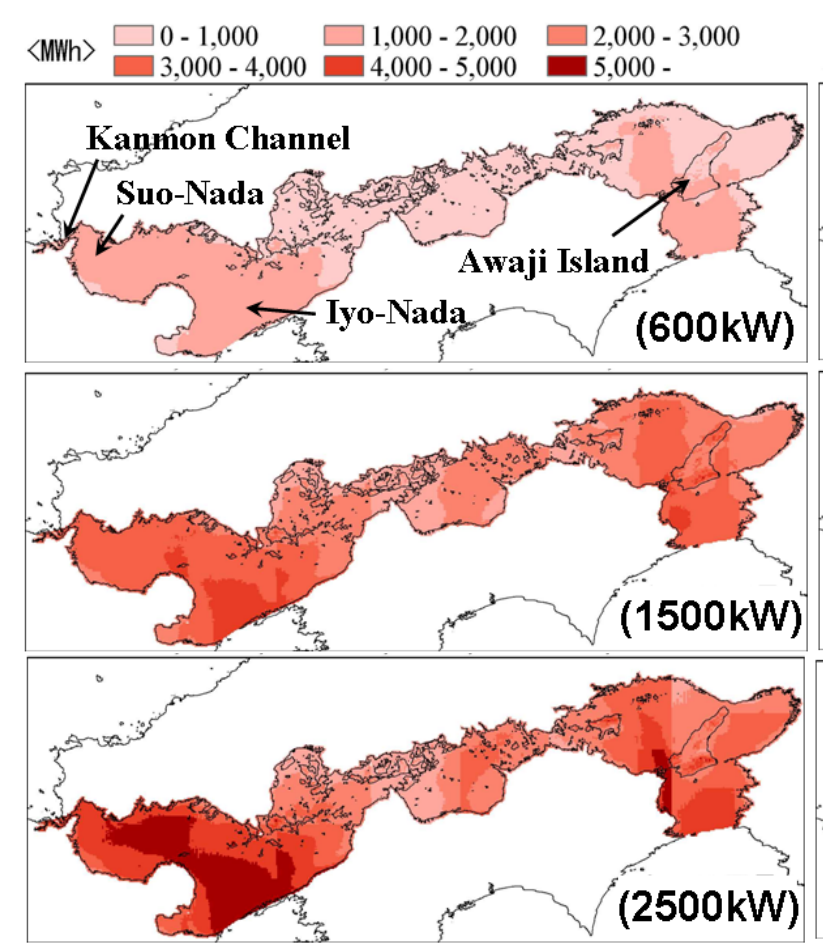

Fig.4 Difference of electric power production due to rated power

extremely larger-scale wind turbines could lead to excessive facility investment although the larger-scale wind turbines can generate more energy. It is important to employ the appropriate scales of wind turbines considering the wind conditions at the wind power generating sites. As shown in Fig.5, the capacity factors exceed $20 \% \sim 30 \%$ in the sea areas from the Suo-Nada to the Iyo-Nada and near Awaji Island.

Fig.6 is the distribution map of the power generating cost based on the underwater substructure when the wind turbine with the rated power of $1500 \mathrm{~kW}$ is employed. In Fig.6, the sea areas deeper than $30 \mathrm{~m}$ are excluded because it is difficult to construct underwater substructures at such deep water sites. The power generating cost is predictably low in the Suo-Nada area due to its good wind conditions and vast shallow waters. It is found that the power generating cost is significantly low particularly along the coastline from the Kanmon Channel to Ube City in Yamaguchi Prefecture. Also in the sea area around the Awaji Island, the power generating cost is low due to its high wind speed. In addition, although the wind speeds are low, the power generating costs are low in the coastal area from Osaka Prefecture to Hyogo Prefecture and the sea areas between Okayama Prefecture and Kagawa Prefecture due to their vast shallow waters. On the contrary, the Iyo-Nada area, where the wind speed is as high as the Suo-Nada area, is excluded in Fig.6 because the water depth is much deeper than $30 \mathrm{~m}$.

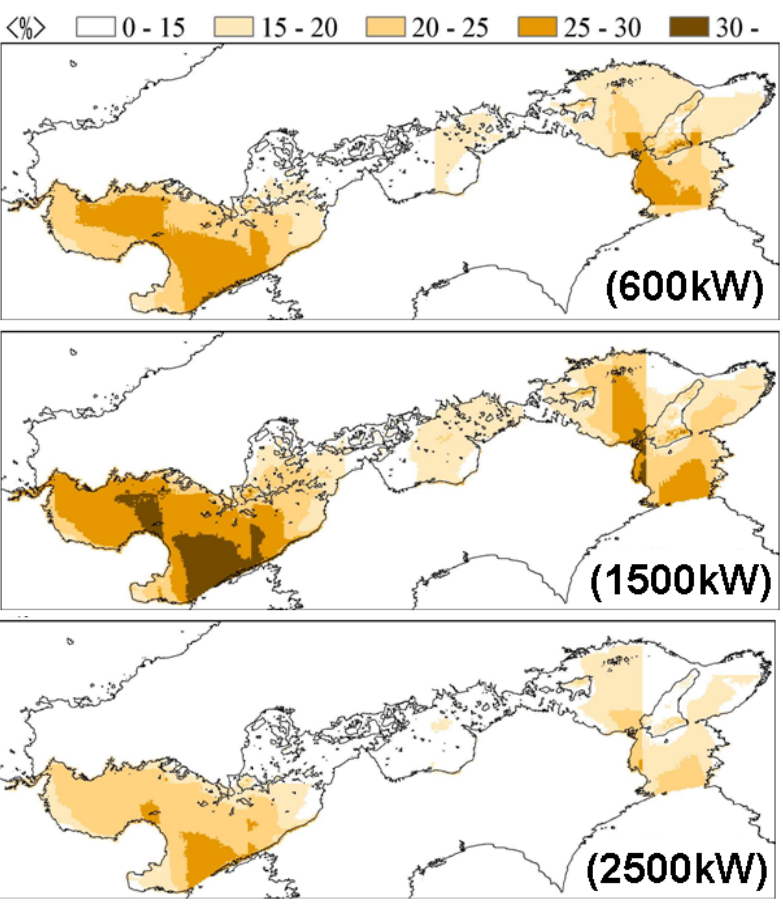

Fig.5 Difference of capacity factor due to rated power

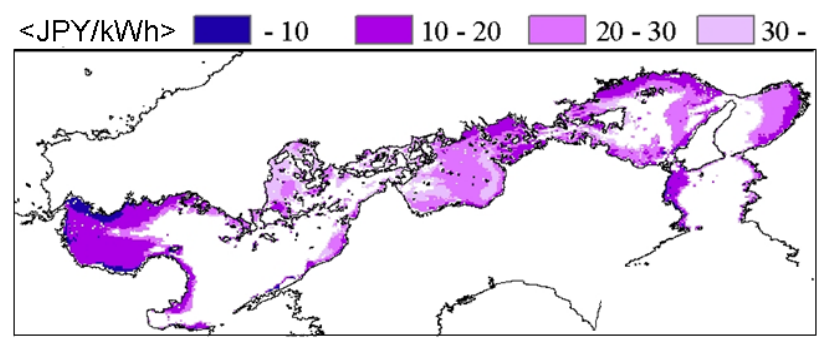

Fig.6 Power generating cost based on underwater substructure (Wind turbine with the rated power of $1500 \mathrm{~kW}$ )

\section{CONCLUSIONS}

In this study, offshore wind energy potential in the Seto Inland Sea is estimated based on the wind prediction data of LAWEPS, and the sea areas appropriate for offshore wind power generation are investigated by means of GIS analysis considering the constrained conditions such as wind speed, water depth, natural parks and ship lanes.

Assuming that the wind turbines with the rated power of $1500 \mathrm{~kW}$ and the height of $70 \mathrm{~m}$ above the ground are placed at intervals of $520 \mathrm{~m}$, possible annual electric power production was estimated at $247 \mathrm{TWh}$ in the whole Seto Inland Sea. This power production corresponds to more than $400 \%$ of the electric power supply in the Chugoku district. Moreover, it was estimated at $32 \mathrm{TWh}$, which corresponds to $60 \%$ of the electric power supply in the Chugoku district, even under the strictest constrained conditions. Although the Seto Inland Sea has been regarded to be inappropriate place for wind 
power generation, these results imply that the offshore wind energy in the Seto Inland Sea is highly promising as an alternative energy source to fossil fuels.

There are many shallow waters less than $20-30 \mathrm{~m}$ in the Seto Inland Sea. It is found that the wind energy in these shallow waters corresponds to more than $200 \%$ of the electric power supply in the Chugoku district.

The sea areas where the annual mean wind speeds are higher than $5 \mathrm{~m} / \mathrm{s}$ occupy approximately $70 \%$ of the whole sea area, while those higher than $6 \mathrm{~m} / \mathrm{s}$ drastically decrease to $30 \%$. This means that the wind speeds are less than $6 \mathrm{~m} / \mathrm{s}$ in most areas of the Seto Inland Sea, and hence active utilization of the wind energy with $5 \mathrm{~m} / \mathrm{s}$ level is very important.

According to the distribution of the power generating cost based on the underwater substructure of the offshore wind turbine, the power generating cost is low in the Suo-Nada area due to its good wind conditions and vast shallow waters. Also in the sea area around the Awaji Island, the power generating cost is low due to its high wind speed. In addition, although the wind speeds are low, the power generating costs are low in the coastal area from Osaka Prefecture to Hyogo Prefecture and the sea areas between Okayama Prefecture and Kagawa Prefecture due to their vast shallow waters. On the contrary, the Iyo-Nada area, where the wind speed is as high as the Suo-Nada area, is not appropriate for offshore wind power generation because the water depth is much deeper than $30 \mathrm{~m}$ and then it is difficult to construct offshore wind turbines.

From the comprehensive perspective, the Suo-Nada area near the Kanmon Channel seems to be highly promising as the offshore wind power generation site.

ACKNOWLEDGMENT: The present work was supported partly by the Japan Society for the Promotion of Science (JSPS), under Grant-in-Aid for Exploratory Research, No. 18656127. We would like to acknowledge the generosity of this organization.

\section{REFERENCES}

1) Hiejima, S.: Offshore Wind Farm Plan for Seto Inland Sea. Wind Energy, Vol. 69, pp. 99 - 101, 2004. (in Japanese)

2) Murakami, S., Mochida, A. and Kato, S.: Development of local area wind prediction system for selecting suitable site for windmill. J. Wind Engineering and Industrial Aerodynamics, Vol. 91, Issues 12-15, pp. 1759-1776, 2003.

3) Voivontas, D., Assimacopoulos, D. and Mourelatos, A.: Evaluation of renewable energy potential using a GIS decision support system. Renewable Energy, Vol. 13, No. 3, pp. 333-344, 1998.

(Received February 1, 2009) 